\title{
Piedras viajeras. De las misiones a Buenos Aires
}

Rolling stones. From the jessuit missions to Buenos Aires

Daniel Schávelzon *

\section{Resumen}

El estudio de las piedras y escombro de una pequeña sección de la costa ya totalmente artificial de la ciudad de Buenos Aires, mostró la presencia de dos piedras recién llegadas y muy desgastadas. Por su coloración rojiza, su composición geológica y con la evidencia de tallado manual era de suponer que provenían de la zona de Misiones y que debieron formar parte de uno o dos edificios. Desconocemos de dónde vienen, cómo se hizo ese viaje enorme en distancia y en siglos, pero llegaron en fecha reciente y quedaron sobre la tierra de la costa. Finalmente es solo una curiosidad, deben ser cientos los edificios jesuíticos destruidos en el tiempo y cuyas piedras cayeron al agua; estas dos curiosamente quedaron a la vista a una enorme distancia, y poco antes de salir al océano y perderse para siempre.

Palabras clave: Misiones Jesuíticas, Misiones, piedras talladas

\begin{abstract}
The study of stones and rubble in a small section of the already totally artificial coast of the city of Buenos Aires, showed the presence of two recently arrived and very worn stones. Due to its reddish coloration, its geological composition and the evidence of manual carving, it was assumed that it came from the Misiones area and that it must have been part of buildings. We do not know where they come from, how that enormous trip was made in distance and in centuries, but they arrived recently and stayed
\end{abstract}

\footnotetext{
*Investigador Superior del CONICET. Email: dschavelzon@ fibertel.com.ar
} 
over de muddy coast. Finally it is just a curiosity, there must be hundreds of Jesuit buildings destroyed in time and whose stones fell into the water; these two, curiously, were visible at a great distance, and shortly before leaving the ocean and lost forever.

Key words: Jesuit Missions, Misiones, carved stones

Recibido: 25 de octubre de 2017.

Evaluado: 24 de noviembre de 2017. 


\section{Presentación}

¿Es posible que una piedra arrojada -o caída- en el río, sea el Paraná o el Uruguay o a través de algunos de sus centenares de afluentes, llegue por arrastre hasta Buenos Aires? Y si eso fuese posible, ¿cómo saber de dónde viene, cuándo se descartó o para qué servía, suponiendo que no fuese algo natural? ¿Podría provenir de algún edificio de las Misiones Jesuíticas si la piedra coincide en forma y composición aunque la distancia a recorrer sea inconmensurable?

Estas son las preguntan que surgen de un hallazgo inusual y cuyas respuestas son, al menos por ahora, difíciles de contestar. Pero vale la pena presentar el tema para abrir un diálogo que puede permitir resolver al menos las preguntas en el futuro. A veces la arqueología, al recorrer sectores de la ciudad que parecen marginales o que acumulan basura de una u otra forma, suele arrojar sorpresas. La costa de la ciudad ya ha mostrado ser un acumulador de objetos de todo tipo -hasta flora y fauna incluidas- llegados de largas distancias.

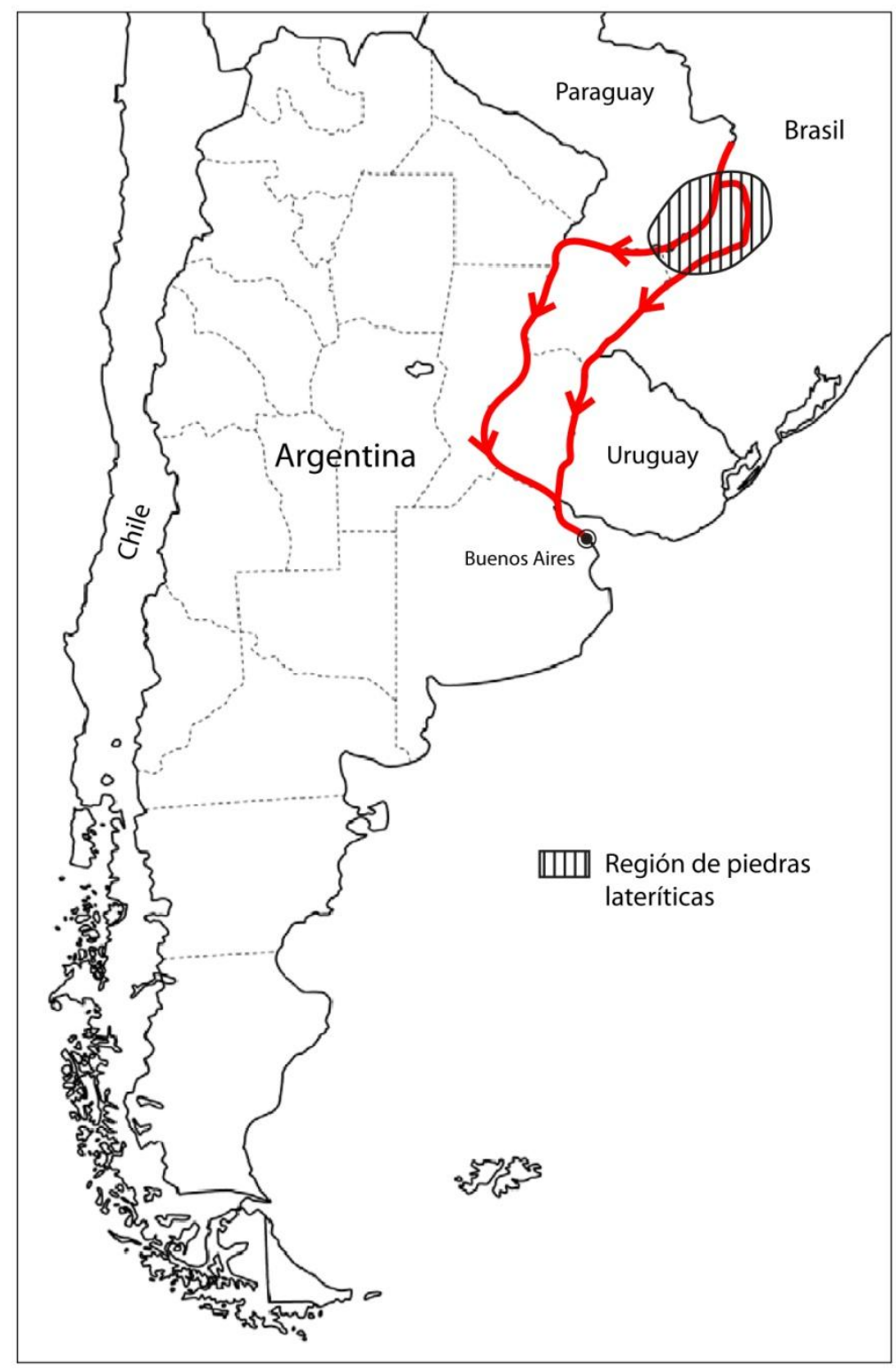

Fig. 1 Mapa del posible desplazamiento de las piedras desde las Misiones hasta Buenos Aires 


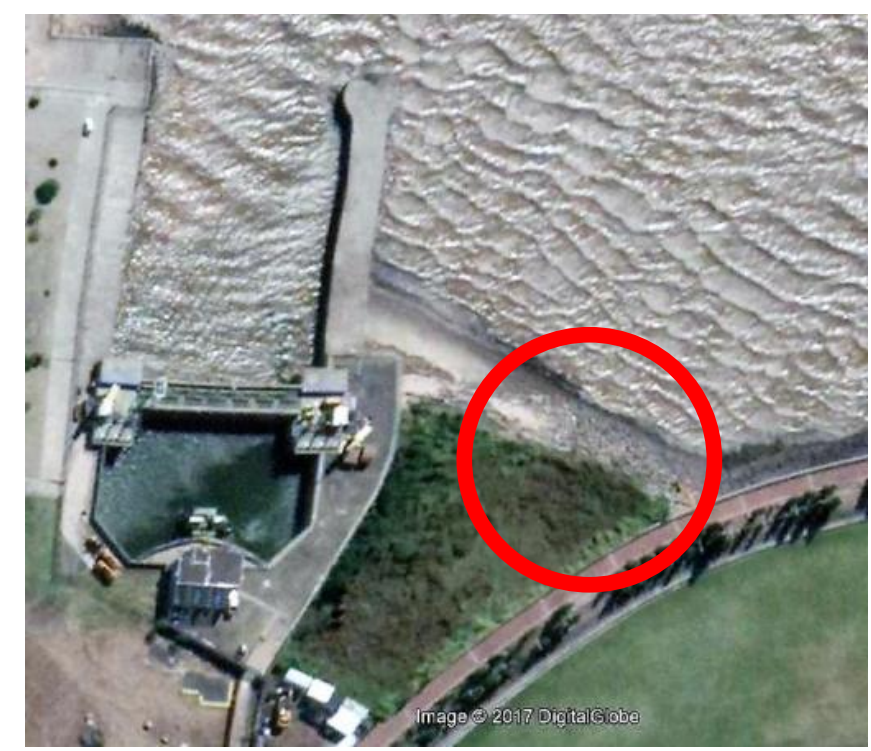

Fig. 2 Único sector de playa en la zona norte de la ciudad, se observa la acumulación de escombro llegado en las bajantes del río. Entre Ciudad Universitaria y el Parque de la Memoria.

\section{Las condiciones del hallazgo}

En el estudio de un área de la costa de la ciudad de Buenos Aires, entre Ciudad Universitaria y el Parque de la Memoria se identificaron dos piedras de arenisca roja con evidencias de tallado manual. Se destacaban a la vista entre los miles de desperdicios y piedras de todo tipo que llegan habitualmente arrastradas por las corrientes del río y que hacen largos viajes hasta desgastarse casi totalmente, o perderse en la inmensidad del océano. Y a su vez estaban mezcladas con el escombro de los rellenos de la costa de la ciudad. Es decir: se encontraron sobre la costa de hoy, no enterradas en la costa antigua -o en las muchas costas que hubo cada vez que se rellenó-, lo que habla de un arribo reciente, es decir menos de tres años en que se completó ese sector con el cerramiento del cauce del arroyo Vega. Si hubiese sido antes estarían enterradas bajo el escombro puesto posteriormente. Estaban a su vez casi sobre el agua de la orilla, unos treinta metros una de la otra, y son fácilmente separables de las piedras y objetos llegados y/o llevados al lugar como rellenos, lo que allí es básicamente hormigón y mampostería de ladrillos con cemento, además de deshechos plásticos recientes.

En el lugar, único fragmento de playa entre murallones de hormigón, el escombro está acumulado en el lado Este, es decir que es lo traído por el Río de la Plata en las bajantes en las que se observa el descenso de camalotes y troncos flotantes de gran tamaño. En el otro extremo de esa playa se conserva la arena colocada hace tres años y no hay basura plástica liviana.

Las dos piedras encontradas mostraban haber sido dejadas por el agua sobre el barro de la costa en fecha reciente. Vale la pena destacar que esa costa hace unos tres años fue cubierta con arena y bloques de basalto oscuro para evitar la erosión, por lo que esto fue arrojado por el agua con posterioridad. Es decir que las trajo el río, no son parte de lo preexistente arriba de la orilla por más que sea una costa artificial. Eso lo destaca la estratigrafía que ha formado el agua al cortar los rellenos pocos varios metros más adentro de la costa actual y cuya observación muestra la composición de las diversas capas que cubren la tosca antigua. 


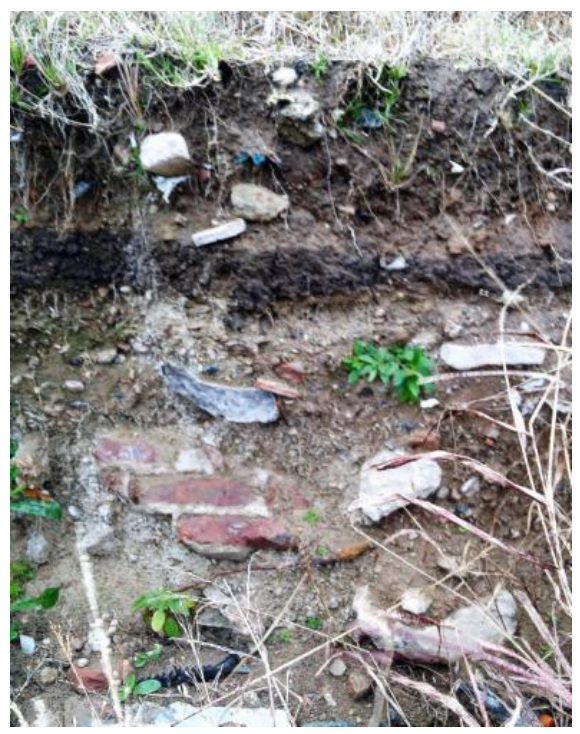

Fig. 3 Superposición de estratos cortado por una creciente: el relleno inferior es moderno de mampostería de cemento y ladrillos, y las capas superiores de tierra negra y escombro son recientes para nivelar el lugar.

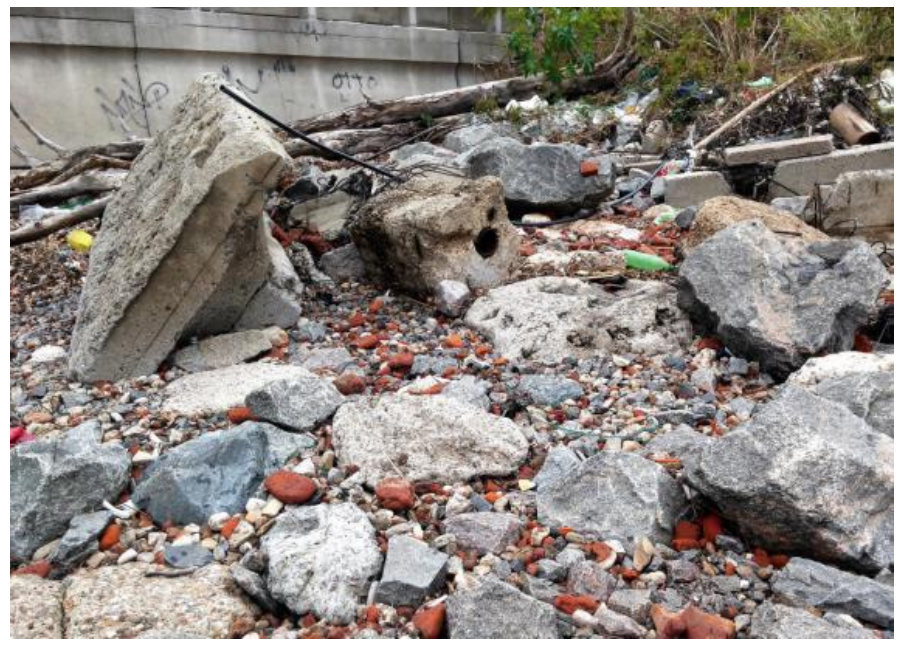

Fig. 4 Contexto del hallazgo: bloques de hormigón y mampostería reciente entre el basalto de protección de la costa, y pequeños ladrillos rodados.

\section{Las dos piedras halladas}

La de mayor tamaño es de forma triangular con la base curva, de unos 40 por 35 $\mathrm{cm}$ y de poco más de cinco centímetros de espesor. El desgaste es fuerte y típico del rodamiento por agua. Es un triángulo que, dado el ángulo de su extremo (36 grados) era parte de un decágono plano. Es decir un piso o parte de una estructura circular de diez fragmentos iguales. En una de sus caras tiene muy desgastada la marca de un círculo que fue hecho después de cortadas las piedras, y seguramente ya puestas una al lado de la otra y en su lugar, ya que la mitad del agujero quedaba sobre la piedra de al lado. Las tres caras laterales de la piedra presentan evidencias de trabajo con una herramienta dura, seguramente hierro, que fue lascando bifacialmente todo el ancho hasta obtener la forma deseada. Mucho se ha borrado por el desgaste del agua pero no presenta tantos síntomas de rodamiento quizás por su forma plana, lo que debe haber hecho que sea más arrastrada que girada como es el otro caso que obtuvimos. 
¿Cuál era su función? Suponemos que la triangular era la base de alguna pila bautismal, fuente o escultura, que por su peso y forma, o cumplía una función arquitectónica o debía estar sobre el piso formando un círculo soportando algo con pequeñas columnitas.
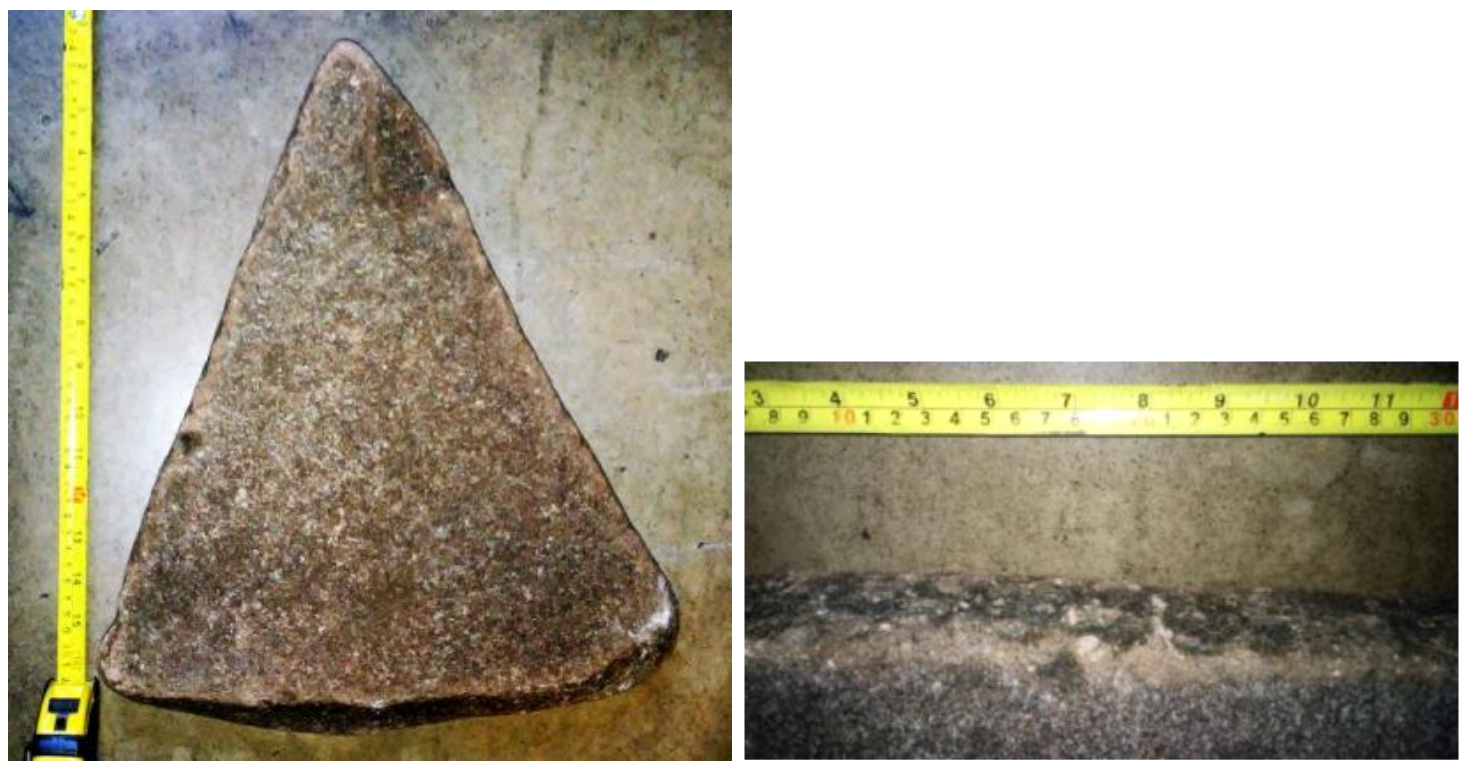

Figs. 5 y 6 Piedra triangular y muestra del tallado por percusión manual en uno de sus bordes.

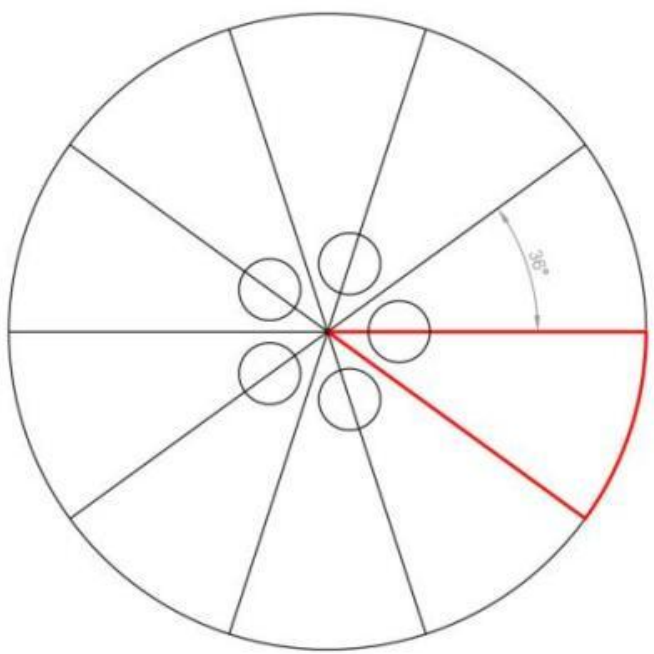

Fig. 7 Reconstrucción de la forma original del círculo y sus probables columnas (Dibujo F. Girelli).

La piedra más pequeña está muy erosionada pero aun conserva partes que indican haber sido rectangular con un lado ligeramente curvado. Está fragmentada midiendo lo que existe 12.5 por 15.0 por $5.0 \mathrm{~cm}$, pero también con una cara curva. Presenta restos de una gruesa capa de cal con fragmentos de ladrillos y tejas. Este fragmento, al ser totalmente informe por el rodamiento es más difícil saber su posible función, aunque al tener una gruesa capa de mortero de cal sí estuvo unida a otra cosa, aunque sólo lo sepamos por una de sus caras ¿era parte de un piso? 
La presencia de cal es indicador de su cronología ya que los jesuitas tuvieron graves problemas para usar este aglomerante que según la bibliografía llegó a la región en 1745 (Levinton 2010). Esto puede ser indicador de que es de las últimas construcciones jesuitas, o incluso de época pos-jesuítica, en que continuó la labor constructiva en piedra hasta inicios del siglo XX (Schávelzon 2016, Schávelzon e Igareta 2017).
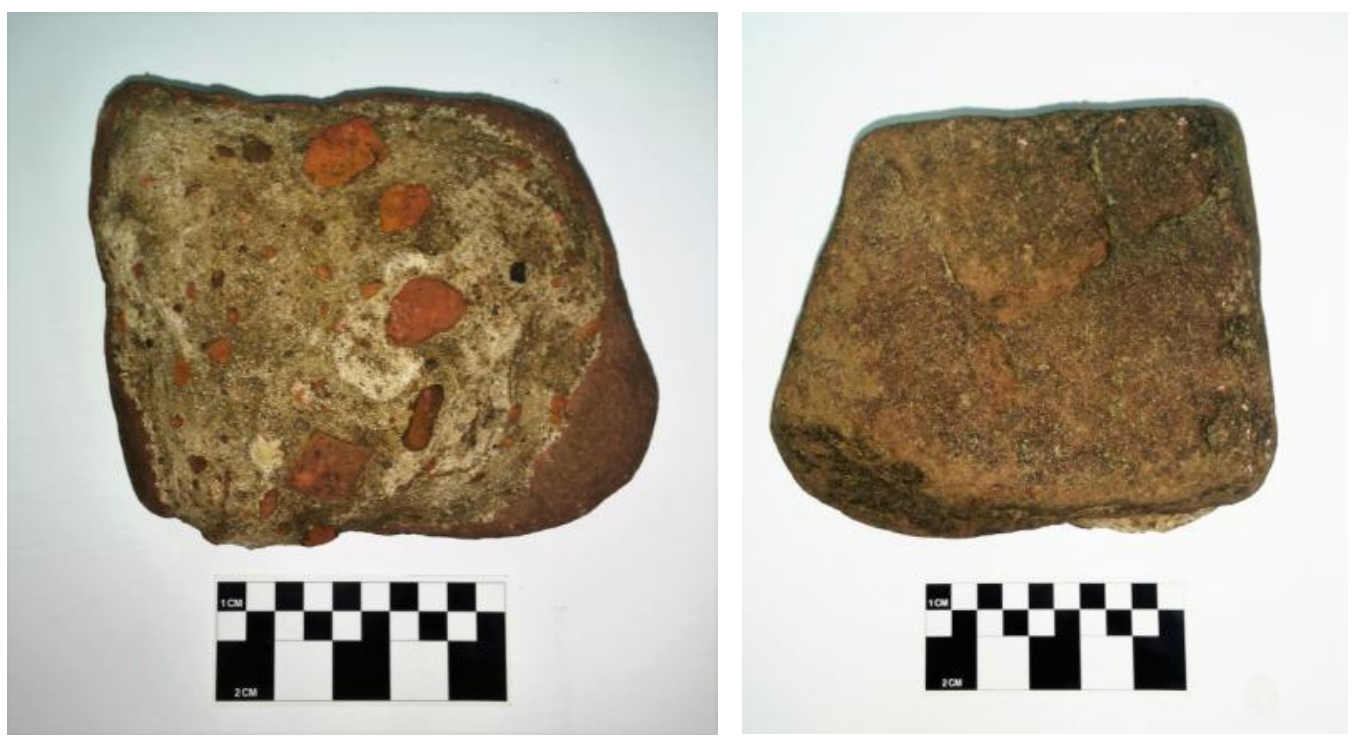

Figs 8 y 9. Fragmento de piedra formateada rectangular con mortero de cal, ladrillo y tejas en una de sus superficies.

\section{El origen y su recorrido}

Cada año llega arrastrado por los grandes ríos, cerca de ochenta millones de toneladas de arena, limo y arcilla, y conforman los sedimentos del estuario llamado Delta. Si bien esto es sedimento liviano y el estudio de los procesos de arrastre fluvial son temas de especialistas, la arqueología está acostumbrada a este fenómeno: la ciudad de Cayastá fue abandonada hacia 1650 por que la mitad de ella ya había sido arrastrada por el río y aun su cerámica puede verse en ambas costas por kilómetros. Quienes trabajamos en sitios costeros de ese río vemos como todos los días es arrojada cerámica guaraní de tamaño medio (hasta 10/15 centímetros) con cada crecida. Y toda clase de basura. Pero no teníamos referencias a piedras de cierto porte quizás porque no fueron identificadas ni estudiadas. Hasta la fecha nunca habíamos visto este tipo de piedra en las zonas estudiadas en la costa de la ciudad y menos con evidencia de trabajo manual. Por ejemplo, la Reserva Ecológica de Buenos Aires la costa se llena de ladrillos y materiales de construcción extremadamente desgastados, a veces hasta ser perfectamente redondos, pero no hay forma de conocer su procedencia la que puede ser lejana o cercana. Una experiencia arqueológica fue la hecha por un equipo subacuático en la zona de Núñez, la que encontró además de botellas y basura arrastrada por el río, una enorme caja fuerte de hierro a más de cincuenta metros de la orilla (García Cano, 1995, com. personal).

No hay forma de conocer con certeza el origen de estas tallas, al menos hasta que no exista un relevamiento por sitio con sus análisis granulométricos y de composición. Ya el P. Sánchez Labrador indicaba la enorme diferencia entre las piedras "Itaquí" -el otro nombre local-, generado por la cantidad de agua en su interior, que la ablanda o endurece, o los granos oscuros o claros y sus dimensiones lo que modificaba la resisten- 
cia. Y los problemas que hubo hasta que se aprendió a distinguir estas diferencias (Furlong 1946, pp. 231-233).

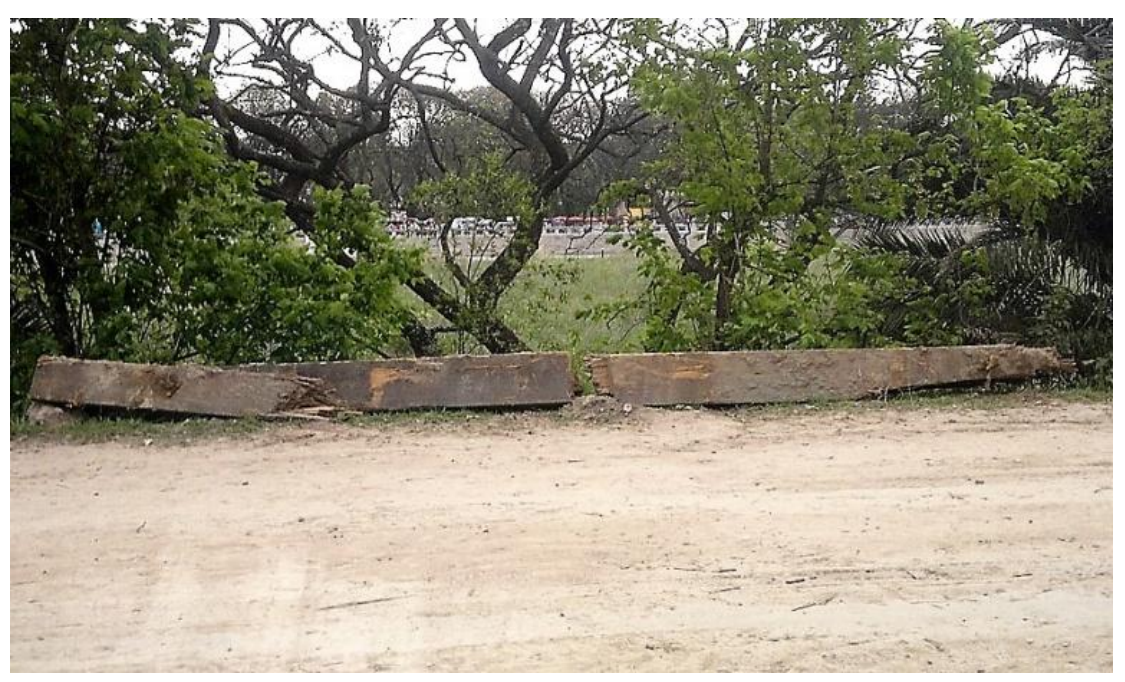

Fig. 10 Pilar de seis metros de altura proveniente de un muelle de la zona de El Tigre, de más de veinte metros de largo, traído por la corriente a la Reserva Ecológica (las roturas fueron hechas para moverlo), en el año 2012.

Asumiendo el origen de estas piedras en Misiones o el norte de Corrientes, donde existe esta laterita, la distancia recorrida es enorme: por el Uruguay al menos 850 kilómetros en línea recta, por el Paraná unos 1200 kilómetros o más. Y si llegó a los ríos más grandes por un río secundario y con los recodos, además de los recodos y saltos, y rápidos, las distancias se alargan. A esto debemos agregar que es muy posible que las piedras hayan pasado las represas como Yaciretá antes de su construcción, porque de otra forma hubiese sido en extremo difícil sino imposible hacer ese viaje. Y suena lógico ya que si tomamos como fecha el final del siglo XVIII, son más de doscientos años, por lo que esa zona pudo cruzarse un siglo antes que cualquier represa.

\section{El origen geomorfológico}

Las piedras son lateritas de origen volcánico, descompuestas por el agua y de marcado color rojo característico producido por la alta presencia de óxido de hierro. Son blandas al extraer pero endurecen con el tiempo al oxidarse el hierro en contacto con el oxigeno; eso las hizo favoritas para la arquitectura jesuítica y posterior (Aleva 1994, Tardy 1997). En el país no hay otros yacimientos de este material o construcciones hechas con él fuera de Misiones y el norte de Corrientes.

\section{Bibliografía}

Aleva, G. J. (Editor), (1994). Laterites. Concepts, Geology, Morphology and Chemistry. Wageningen: ISRIC.

Furlong, G. (1946). Artesanos argentinos durante la dominación colonial. Buenos Aires: Huarpes. 
Levinton, N. (2009). San Ignacio Miní: la identidad arquitectónica. Buenos Aires: Contratiempo Ediciones.

(2010), "Un aporte para la datación cronológica de las ruinas de las Misiones Jesuíticas". En: Arquitectura de las Misiones Jesuíticas, www.arquitecturamisionera.blogstop.com.ar/ (Acceso 7/6/2017).

Tardy, Y. (1997). Petrology of Laterites and Tropical Soils. Rotterdam: Brookfield.

Schávelzon, D. (2016). Teyú Cuaré: Arquitectura en piedra en Misiones en el siglo XX. http://www.iaa.fadu.uba.ar/cau/?p=7625 (Acceso 5/6/2017).

Schávelzon, D. y A. Igareta (2017). Arqueología de un refugio nazi en la Argentina: Teyú Cuaré. Buenos Aires: Sudamericana. 